ledge involves surgery almost as much as it does general medicine. The need for the special knowledge arises partly from the fact that psychiatry shares certain symptoms and signs as well as a common underlying structure with somatic medicine, ${ }^{1-3}$ partly out of the distortion which mental disorder can give to the usual clinical picture of somatic illness. ${ }^{1}$ is

The new M.R.C.P. London Part III could certainly test this special knowledge-for example, by questions on the differential diagnosis to be considered by a psychiatrist when presented with such symptoms (in various combinations or in isolation) as lethargy, palpitations, tremor, sweating, loss of appetite, and wasting, ${ }^{2}$ but the psychiatric candidate could probably escape adequate scrutiny in other ways were he to pass Part II outright, since it is not designed as a psychiatric qualification. If, however, the new M.R.C.P. London Part III is to become the coveted outward sign for specialists in the field of mental health, aspirants to these honours will be presented with the added difficulty of having to do well enough in Part II to be allowed to proceed to Part III, although not so well as to pass Part II outright lest they then be open to the criticism that they have not been adequately examined in their subject.

It seems to me that the Royal College of Physicians, London, may have done itself and psychiatry a disservice by altering its postgraduate diploma in the way it has, for the doubtful advantage of becoming top heavy with the large numbers of specialists likely to be required in psychiatric hospitals for some time yet to come. The M.R.C.P. London may in fact have been unnecessarily debased since the kind of special somatic knowledge required by workers in the mental health field is probably better tested by the D.P.M. ${ }^{67}$ and special M.D.s. ${ }^{78}$ I am sure the Royal College need not have feared that it might lose psychiatry from the general medical fold, nor that it might have too few psychiatrists amongst its Members, since the M.R.C.P. is likeiy to have remained a requirement for consultants or at teaching hospitals, especially general ones where the emphasis must inevitably be placed on and standing gained for psychiatry with psychosomatics.-I am, etc.,

Ide Hill, Kent. J. P. CRAWFORD.

References

Crawford, J. P., Practitioner, 1954, 173, 696.

Guy's Hosp. Gaz., $1955,69,48$.

Lancet, 1961, 2, 487

Marchand, W. E.. Sarota, B., Marble, H. C.

Leary, T. M., Burbank, C. B., and Bellinge

M. J., New Engl. F. Med., 1959, 260, 580 .

5 Crawford, J. P., Brit. med. $\breve{f}$., 1962, 2, 1330.

二 Lancet, 1964, 1, 878 .

_- Brit. med. 'f., 1964, 1, 773.

\section{Neonatal Thrombocytopenia and Thiazide Drugs}

SIR,-The article on the controlled trial of chlorothiazide in the treatment of preeclampsia by Mr. D. N. Menzies (21 March, p. 739) is an encouraging example of the type of study that is so urgently needed to assess the advantages of recently introduced drugs over the more traditional measures.

I feel obliged, however, to make the following comments. The chlorothiazide-treated patients were considered to have done better than those on low-salt diets and phenobarbitone, in that fewer admissions to hospital were required for pre-eclampsia. The bene- fits of chlorothiazide over the phenobarbitone regimen appeared marginal and the statement is made that "chlorothiazide is as good as phenobarbitone, rest, and diet in controlling blood-pressure." Chlorothiazide proved to be effective in controlling weight gain, which is hardly surprising, and since a weight increase of more than 2 pounds $(0.9 \mathrm{~kg}$.) in a week resulted in hospital admission this may have been the major factor in the benefit seen in the thiazide-treated group. The conclusion reached was that chlorothiazide was significantly better than phenobarbitone, rest, and diet in the out-patient management of mild pre-eclampsia.

I do not wish to appear unduly critical, but would like to draw attention to the hazards of treatment with thiazides, as they are undoubtedly being widely used in the management of this condition and, as always, the risks of drug therapy must be weighed against the expected benefits. It is surprising that Mr. Menzies did not comment further on the neonatal death caused by thrombocytopenia, as this may indeed have been produced by chlorothiazide. This condition is a recognized but rare complication of thiazide administration in adults and there is no reason to assume that it will not occur in the metabolically immature infant. A recent publication $^{1}$ describes seven cases of neonatal thrombocytopenia associated with maternal thiazide intake and there was one death. Most of these cases occurred with rather prolonged treatment in that five of the seven mothers had taken the drugs for three weeks or longer and in one instance the duration was unknown. The mother of the thrombocytopenic infant in Mr. Menzies's paper is described as having taken $24 \mathrm{~g}$. of chlorothiazide over a period of six weeks. It may be that the duration of treatment is related to the development of this lethal side-effect.
The pregnant woman is also particularly vulnerable to other side-effects of the thiazide diuretics. Diabetes may be aggravated and as a result of hypokalaemia pyelonephritis may be more severe. ${ }^{2}$ One case of venous thrombosis in the series is mentioned. It is implied, but not stated, that this patient was in the thiazide group and no clinical details are given. Implication of a drug in this type of situation is always difficult, but as thrombophlebitis is such a dangerous condition in this population it becomes most important to ascertain whether there really is an increased incidence. The high doses of chlorothiazide advocated can hardly be described as universally safe in the light of the known complications of thiazide therapy, and caution should be exercised in advising early and prolonged treatment in pregnancy. If mild pre-eclampsia can be managed satisfactorily by safer methods the thiazide diuretics should be reserved for the more advanced cases and indiscriminate use avoided. It is important to retain our perspective. Chlorothiazide and related compounds are extremely valuable drugs with definite indications for use. It may well be that it is more dangerous to spend a week in hospital than to take thiazides for a month, but further carefully controlled studies are required.-I am, etc.,

\section{F. PRESCOTT.}

\section{Division of Clinical Pharmacology,}

School of Medicine

Baltimore, Maryland, U.S.A.

\section{REFERENCES}

Rodriguez, S. V., Leikin, S. L., and Hiller,
M. C., Nerw Engl. F. Med. 1964, 270, 881 . M. C., Nerw Engl. F.
Lancet, 1964, 1, 923 .

** A leading article on Neonatal Thrombocytopenia and Thiazide Drugs appears at p. 1395._ED., B.M.F.

\title{
Tetanus Prophylaxis
}

SIR,-Yet one more letter (Mr. A. WebbJones and Mr. F. F. Sandor, 2 May, p. 1187) appears in support of Dr. Colleen A. Cox and her colleagues (30 November 1963, p. 1360) in giving up the use of tetanus antitoxin (A.T.S.) as being inefficient. The prophylaxis recommended by Dr. Cox is based on antibiotics. In the last year since this treatment has been propagated I know of two deaths from tetanus and three other cases which fortunately recovered (two in our own unit) following on this treatment. It would seem that the treatment proposed by Dr. Cox is not a reliable form of prophylaxis.

I have yet to be convinced that treatment by A.T.S. is inefficient. In my department in the last 15 years no patient who has been given A.T.S. has developed tetanus (about 100,000 patients). Further, I have served previously for eight years in Lagos in charge of a busy hospital where A.T.S. was given as routine to all those with contaminated wounds. Only one patient developed tetanus. Yet in the same time we were treating 200 patients a year with clinical tetanus who had not received hospital treatment primarily for their wounds. There were no antibiotics in those days to back up the use of A.T.S.

It is agreed there is a danger of allergic reactions due to the use of A.T.S. It has been the practice in my department to inject A.T.S. and procaine penicillin in the same syringe where prophylaxis has been required. Six severe reactions have occurred in the last 15 years in the same 100,000 patients. However, for a short time last year, owing to our failure to brief new nurses, A.T.S. was given in a separate syringe from the procaine penicillin. Immediate allergic reactions became remarkably frequent. Since the old practice of mixing A.T.S. with procaine penicillin in the same syringe was reverted to these reactions stopped. This suggests that, by one means or another, the procaine penicillin does minimize the chance of acute allergic reactions.

Without doubt, any department which administers A.T.S. for prophylaxis should consider itself professionally liable to persuade these patients to complete a course of active immunization by means of tetanus toxoid. It is interesting to note in the first 100 cases of wounds seen last year in this department that eight patients had previously been given A.T.S. but had not been subsequently immunized: this year only three out of $100 \mathrm{had}$ not been subsequently immunized. This small sample suggests that immunization is being increasingly carried out after giving A.T.S. Again, in the first 100 cases last year 44 patients had been previously immunized against tetanus. This year 58 patients had been previously immunized. It is hoped from the evidence of this small sample that the propaganda for active im- 